Int. J. Electrochem. Sci., 15 (2020) 5803 - 5820

International Journal of

ELECTROCHEMICAL

SCIENCE

WwW.electrochemsci.org

\title{
Loofah Sponge-Derived Sulfur-Rich Porous Carbon with Micropores and Small Mesopores as High Performance Anode Material for Lithium Ion Batteries
}

Feng Chen ${ }^{1,+}$, Jiangang Ren ${ }^{1,+}$, Lulu $\mathrm{Ma}^{1}$, Xinyu Luo ${ }^{2}$, Nana $\mathrm{Wu}^{1}$, Shenke $\mathrm{Ma}^{1}$, Bing $\mathrm{Li}^{1}$, Zhiming Song ${ }^{1, *}$ Xiangyang Zhou $^{2, *}$

${ }^{1}$ School of Resource and Environment, Henan University of Engineering, No. 1, Xianghe Road, Zhengzhou 451191, China

${ }^{2}$ School of Metallurgy and Environment, Central South University, Lushan South Street 932, Yuelu

District, Changsha 410083, China

*E-mail: songzhimin1961@ hotmail.com (Z.S.); hncsyjy308@163.com (X.Z)

F.C. and J.R. contributed equally to this work.

doi: $10.20964 / 2020.06 .59$

Received: 31 January 2020 / Accepted: 7 March 2020 / Published: 10 May 2020

We reported on the preparation of sulfur-rich porous carbon (SPC) with micropores and small mesopores from natural biomass (loofah sponge) via a high yield, cost-effective, and environmental friendly approach for the first time. The as-obtained SPC was vested with the comprehensive superiority of featuring unique microporous and small mesoporous carbon nanostructure, ultrahigh specific surface area $\left(3211.2 \mathrm{~m}^{2} \mathrm{~g}^{-1}\right)$, inherent doping of sulfur $(2.98 \mathrm{wt} \%)$, and good electronic conductivity $\left(1.9 \mathrm{~S} \mathrm{~cm}^{-1}\right)$. The SPC, as the anode material in lithium ion batteries (LIBs), delivered glorious electrochemical characteristics, including a large reversible capacity of $1264.4 \mathrm{mAh} \mathrm{g}^{-1}$ at 0.2 $\mathrm{C}$, excellent rate performance (538.6, 351.1, and $256.3 \mathrm{mAh} \mathrm{g}^{-1}$ at 2, 5, and $10 \mathrm{C}$, respectively), and good cycle stability over 400 cycles at $2 \mathrm{C}$ (with $0.087 \%$ capacity fading per cycle). The enhanced electrochemical property of SPC was largely ascribed to the cooperative effect of the unique structural features and sulfur doping, which not only could enhance electrochemical activities for lithium storage, but also could promote rapid transfer of lithium ions and electrons. Furthermore, we believe that this work would provide a novel perspective on the reasonable designing of high-energy carbonaceous anode materials.

Keywords: loofah sponge; sulfur-rich carbon; micropores and small mesopores; biomass; lithium ion batteries

\section{FULL TEXT}


(C) 2020 The Authors. Published by ESG (www.electrochemsci.org). This article is an open access article distributed under the terms and conditions of the Creative Commons Attribution license (http://creativecommons.org/licenses/by/4.0/). 